\title{
Structural Performance of Tapered Tall Buildings
}

\author{
Kyoung Sun Moon \\ Yale University School of Architecture
}

\begin{abstract}
Structural efficiency of tapered tall buildings has well been recognized, and many tall buildings of tapered forms have been built throughout the world. This paper systematically studies the structural efficiency of tapered tall buildings in terms of lateral stiffness. Tall buildings of various heights and angles of taper are designed with different structural systems prevalently used for today's tall buildings, such as braced tubes, diagrids, and core-outrigger structures. The heights of the studied buildings range from 60 to 100 stories, and the angles of taper studied are 1, 2 and 3 degrees. Based on design studies, comparative performances of the various structural systems for tapered tall buildings are presented.
\end{abstract}

Keywords: Tapered tall buildings, diagrids, braced tubes, core-outrigger structures.

\section{Introduction}

For today's very tall buildings built with higher strength structural materials, it is common that lateral stiffness requirements against wind loads rather than strength govern their structural design (Connor, 2001). Tapered forms employed for tall buildings provide greater lateral stiffness toward the base because they naturally produce greater structural depth against lateral loads toward the base. Tapered forms also help reduce wind loads applied to tall buildings. As the angle of taper is increased, the lateral shear and overturning moments are decreased. Furthermore, tapered forms help tall buildings prevent shedding organized alternating vortices that can cause resonance conditions. Therefore, tapered tall buildings are less susceptible to severe across wind direction vibrations than prismatic tall buildings.

Tall buildings are built with an enormous amount of building materials including structural materials coming from our limited natural resources. As the building height is increased, the required amount of structural materials to resist lateral loads increases exponentially due to the "premium for height" (Ali and Moon, 2007). 
Therefore, it is essential to develop efficient structural systems as well as building forms to save our limited resources and construct more sustainable built environments. Tapered forms are inherently one of the most efficient structural forms for tall buildings.

This paper systematically examines comparative efficiency of various structural systems employed for tapered tall buildings, based on lateral stiffness. Tall building structural systems prevalently used today include diagrids, braced tubes and core-outrigger structures. Tapered tall buildings of 60,80 and 100 stories are designed with these structural systems and their structural performances are studied comparatively. The corresponding height-to-width aspect ratios of the 60-, 80- and 100-story tall buildings in their non-tapered prismatic forms are 6.5, 8.7 and 10.8, respectively. The angles of taper studied are 1, 2 and 3 degrees.

\section{Tapered Braced Tubes}

In order to study the structural performance of tapered forms employed in braced tubes, 60-story buildings of various angles of taper are designed with braced tubes. A non-tapered prismatic braced tube structure is designed first. The building's typical plan dimensions are $36 \mathrm{~m} \times 36 \mathrm{~m}$ with an $18 \mathrm{~m} \times 18 \mathrm{~m}$ core at the center, and typical story heights are $3.9 \mathrm{~m}$. The perimeter braced tube system is designed to carry the entire lateral loads, and the core is designed to carry only gravity loads. The building is assumed to be in Chicago and the ASCE/SEI 7, Minimum Design Loads for Buildings and Other Structures, is used to establish the wind load. This loading condition is used not only for the braced tube but also for the diagrids and core-outrigger structures presented later in this paper.

The braced tube member sizes for the prismatic tower are determined using the stiffness-based design methodology developed by Moon (2010) to meet the maximum lateral displacement requirement of a five hundredth of the building height. Figure 1 shows the 60-story braced tube structures non-tapered and tapered with three different angles of 1,2 and 3 degrees. Since the building width at mid-height is maintained to be the same as the original prismatic tower, each tapered building's gross floor area is the same regardless of the different angles of taper. Member sizes determined for the prismatic braced tube are also used for the tapered ones for preliminary design purposes. The impact of the diagonal angle changes caused by tapering the tower by 1,2 and 3 degrees is minimal in terms of the system's shear 
stiffness. As the building is tapered, however, the building width is increased toward the base where the maximum overturning moment is applied, and consequently the bending stiffness is increased.

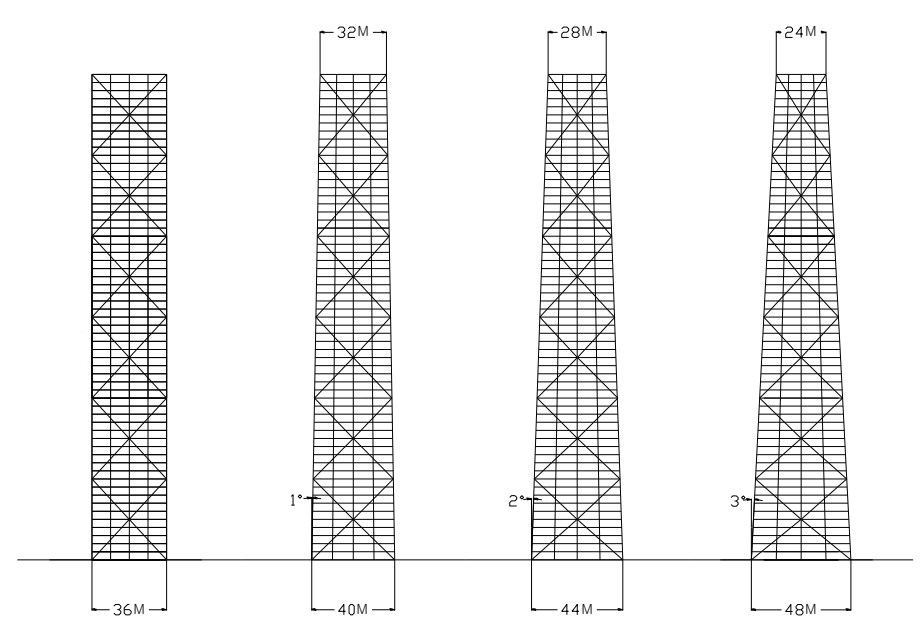

Figure 1. 60-story non-tapered and tapered braced tubes

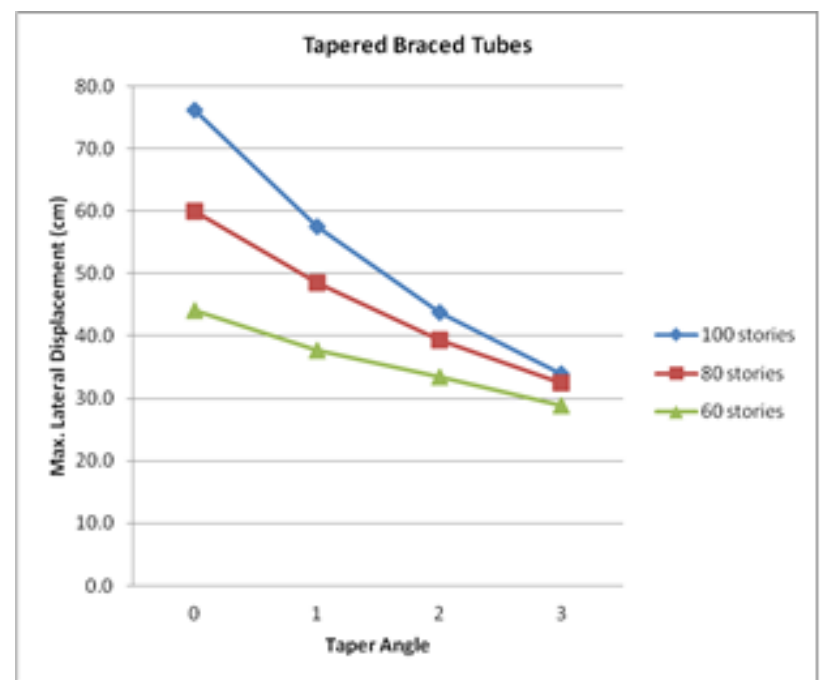

Figure 2. Maximum lateral displacements of the 60-, 80- and 100-story tapered braced tubes 
The maximum lateral displacements of the 60-story tapered braced tubes shown in Figure 1 as well as similarly configured and designed 80- and 100-story tapered braced tubes are summarized in Figure 2 based on SAP2000 analysis results. Lateral stiffness of the braced tube is increased as the angle of taper is increased. Consequently, lateral displacements of tapered braced tubes are reduced as the angle of taper is increased. Further, the rate of displacement reduction due to taper is accelerated as the building becomes taller. The maximum lateral displacement of the 100-story tapered braced tube with its tapered angle of 3 degrees is only about a half of that of the corresponding non-tapered prismatic braced tube of the same height.

\section{Tapered Diagrids}

As another tube type structure with perimeter diagonals, the structural performance of diagrids is similar to that of braced tubes. However, unlike previously studied braced tube structures, which are composed of vertical columns and diagonal bracings, diagrid structures are composed of only diagonal gird members. In order to study the structural performance of tapered forms employed in diagrids, 60-story buildings of various angles of taper are now designed with diagrids. A non-tapered prismatic diagrid structure is designed first. The prismatic building's typical plan dimensions are $36 \mathrm{~m} \times 36 \mathrm{~m}$ with an $18 \mathrm{~m} \times 18 \mathrm{~m}$ core at the center, and typical story heights are $3.9 \mathrm{~m}$. The perimeter diagrid system is designed to carry the entire lateral loads, and the core is designed to carry only gravity loads. Three diamond-shaped sub-modules of the diagrids are placed within the building width of $36 \mathrm{~m}$. Preliminary studies suggest that a configuration with a diagrid module height of eight stories which results in a diagrid angle of 69 degrees as shown in Figure 3 is the near optimal condition.

The diagrid member sizes for the prismatic tower are determined with the stiffness-based design methodology developed by Moon et al. (2007) to satisfy the maximum lateral displacement requirement of a five hundredth of the building height. The lateral shear stiffness of the diagrids is primarily governed by the cross-sectional area and angle of the diagonals. The bending stiffness is governed by the cross-sectional area, angle of the diagonals and building width. As the building is tapered, the building width is increased toward the base where the maximum overturning moment is applied. Consequently, the bending stiffness in relation to the building width is increased in tapered diagrids. 
In terms of diagrid angles, varying angle diagrid structures with diagrid members placed at angles appropriately steeper toward the base could be more efficient for very tall buildings because taller structures behave more like bending beams and diagrid members placed at steeper angles at lower levels provide higher bending rigidity (Moon, 2008; Baker et al., 2009). Thus, in the tapered diagrid structures, diagrid angles are adjusted by changing the module heights as can be seen Figure 3 .

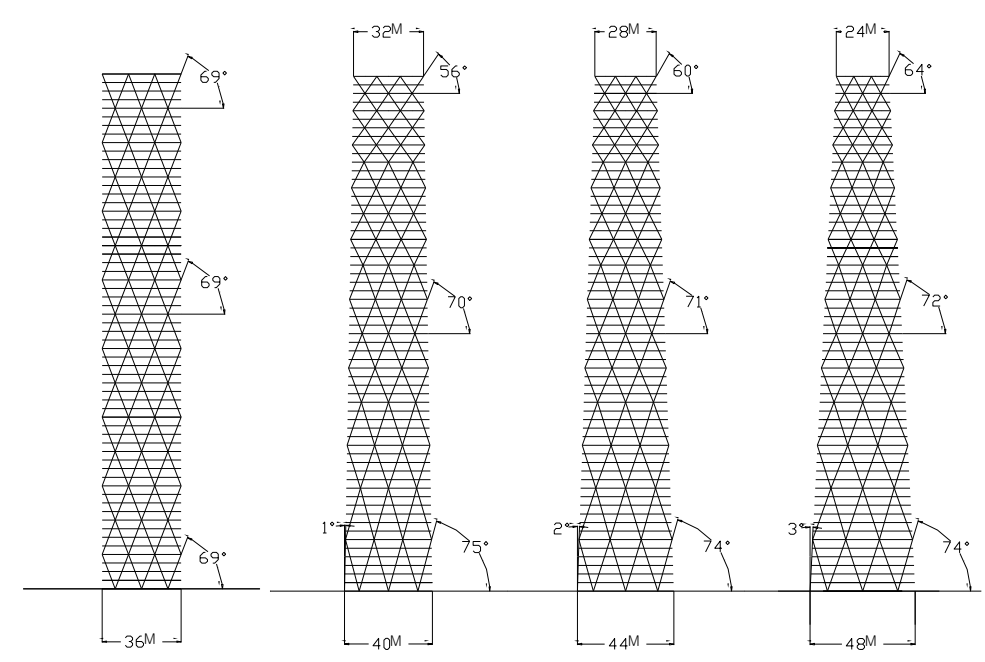

Figure 3. 60-story non-tapered and tapered diagrids

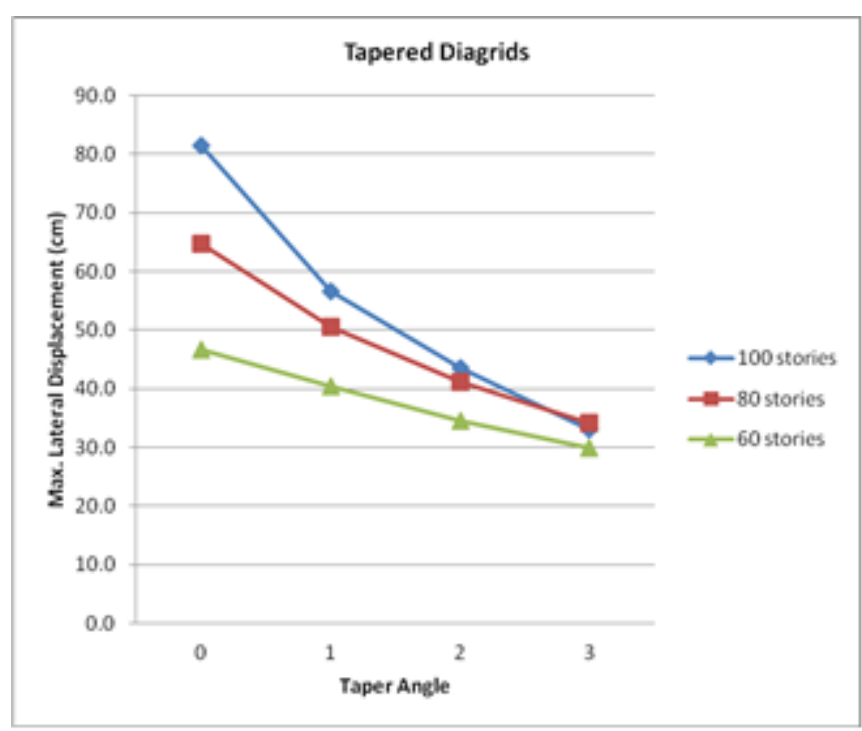

Figure 4. Maximum lateral displacements of the 60-, 80- and 100-story tapered diagrids 
The maximum lateral displacements of the 60-story tapered diagrids shown in Figure 3 as well as similarly configured and designed 80- and 100-story diagrids are summarized in Figure 4 based on SAP2000 analysis results. It clearly shows that the impact of taper becomes greater as the diagrid structure becomes taller. The maximum lateral displacement of the 100-story tapered diagrid structure with its tapered angle of 3 degrees combined with the logical diagrid angle adjustment is only about $40 \%$ of that of the corresponding non-tapered prismatic diagrids of the same height.

\section{Tapered Core-Outrigger Structures}

Core-outrigger structures are another very efficient and prevalently used structural system for today's tall buildings. Sixty-story buildings of various angles of taper are now designed with core-outrigger systems. A non-tapered prismatic core-outrigger building is designed first. The prismatic building's typical plan dimensions are $36 \mathrm{~m} \mathrm{x}$ $36 \mathrm{~m}$ with typical story heights of $3.9 \mathrm{~m}$. Different from the cases with the braced tubes and diagrids, an $18 \mathrm{~m} \times 18 \mathrm{~m}$ core structure at the center is now designed with braced frames to carry not only gravity but also lateral loads. The core in the outrigger system is connected to the perimeter mega-columns through outrigger trusses located at one third and two thirds heights of the building. Other design conditions, including the wind load and the target maximum allowable lateral displacement, are the same as before.

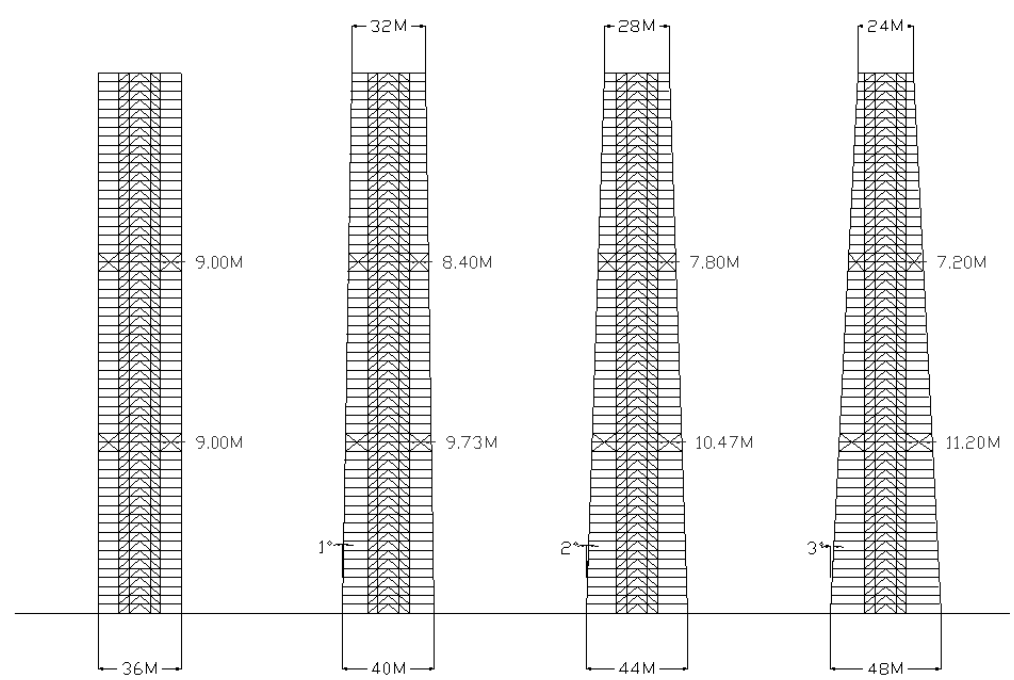

Figure 5. 60-story non-tapered and tapered core-outrigger structures 


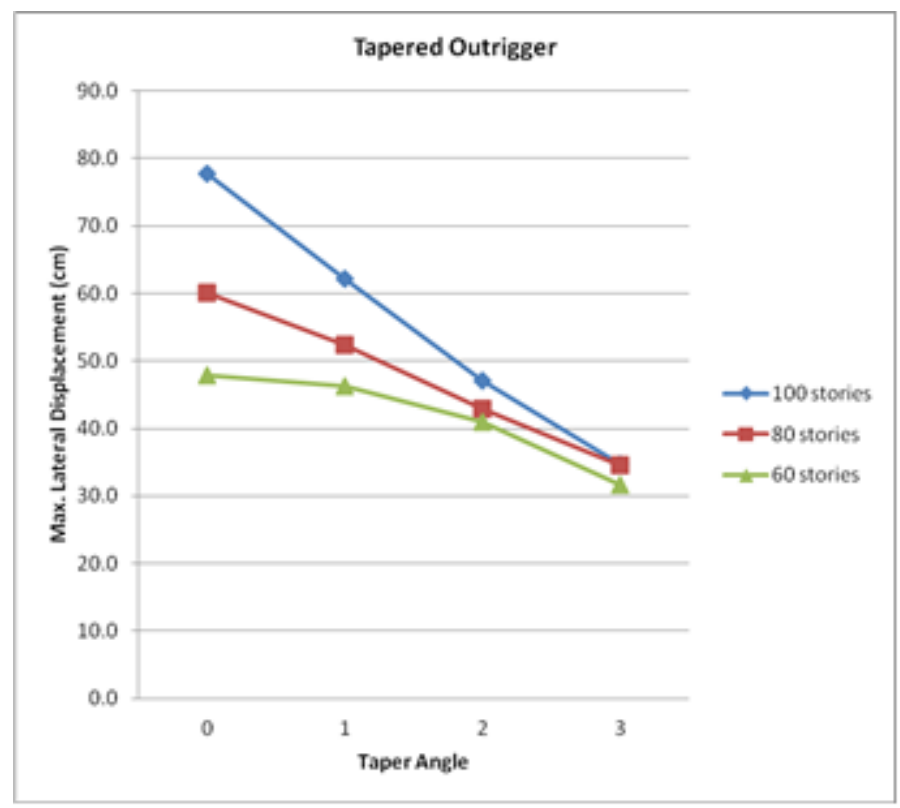

Figure 6. Maximum lateral displacements of the 60-, 80- and 100-story tapered core-outrigger structures

The core-outrigger structure is then tapered with three different angles of 1, 2 and 3 degrees as shown in Figure 5 . Since the building width at mid-height is maintained to be the same, each building's gross floor area is the same regardless of the different angles of taper. By tapering the tower, the distances between the opposite side perimeter mega-columns, which act as counteracting overturning moment arms, become greater toward the base where greater overturning moments are developed and narrower toward the top. This configuration helps increasing lateral stiffness of the system. While the overall building form is tapered, the central braced core is not tapered in this study. Therefore, the lengths of the outrigger trusses that connect the central braced core and perimeter mega-columns are changed accordingly. The length of the outrigger trusses becomes longer toward the base of the building as the angle of taper is increased, and this condition adversely contributes to increasing the lateral stiffness of the tapered core-outrigger system. However, the increased stiffness based on tapering the structure still governs the overall performance of the system.

The maximum lateral displacements of the 60-story tapered outrigger structures shown in Figure 5 as well as similarly configured and designed 80- and 100-story tapered outrigger structures are summarized in Figure 6 . Lateral displacements of 
core-outrigger structures are reduced as the angle of taper is increased. The detailed characteristics of the displacement reduction based on taper in core-outrigger structures are a bit different from those in diagrids and braced tubes due to the different structural configuration of the system, while the overall performance characteristics are still very similar. The lateral stiffness of the tapered core-outrigger structures can be further increased by increasing the stiffness of the outrigger trusses, especially those on lower levels.

\section{Conclusions}

Lateral performance characteristics of tapered perimeter tube type structures, such as diagrids and braced tubes, are very similar, while that of tapered core-outrigger structures is a bit different because of the different structural configuration. Nonetheless, all the systems designed with tapered forms produce superior structural performances than those with non-tapered prismatic forms.

Studies performed in this paper were limited to the static responses of tapered tall building structures. In tall buildings, vortex-shedding induced lock-in phenomena often create the most critical structural design conditions, and tapered forms also help tall buildings prevent shedding organized alternating vortices along the building height. Therefore, tapered forms provide superior static as well as dynamic responses for tall building structures.

\section{References}

Ali, M.M. and Moon K., 2007. Structural Developments in Tall Buildings: Currents Trends and Future Prospects. Architectural Science Review, 50.3, pp 205-223. Baker, W.F., Besjak, C.M., McElhatten, B.J., and Biswas, P., 2009. 555 m Tall Lotte Super Tower, Seoul, South Korea, American Institute of Civil Engineers Structures Congress.

Choi, H., Ho, G., Joseph, L., and Mathias, N., 2017. Outrigger Design for High-Rise Buildings $2^{\text {nd }}$ Edition: An Output of the CTBUH Outrigger Working Group. Chicago: Council on Tall Buildings and Urban Habitat.

Connor, J.J., 2003. Introduction to Structural Motion Control. New York: Prentice Hall. Kowalczyk, R., Sinn, R., and Kilmister, M.B., 1995. Structural Systems for Tall Buildings. Council on Tall Buildings and Urban Habitat Monograph. New York: McGraw-Hill. 
Moon, K., Connor, J. J. and Fernandez, J. E., 2007. Diagrid Structural Systems for Tall Buildings: Characteristics and Methodology for Preliminary Design, The Structural design of tall and Special Buildings, Vol. 16.2, pp. 205-230.

Moon, K., 2008. Optimal Grid Geometry of Diagrid Structures for Tall Buildings, Architectural Science Review, Vol. 51.3, pp 239-251.

Moon, K., 2010. Stiffness-Based Design Methodology for Steel Braced Tube Structures: A Sustainable Approach, Engineering Structures, Vol. 32, pp. 3163-3170.

Simiu, E. \& Scanlan, R. H., 1996. Wind Effects on Structures: Fundamentals and Applications to Design. $3^{\text {rd }}$ Edition. New York: Wiley.

Smith, B. \& Coull, A., 1991. Tall Building Structures: Analysis and Design. New York: Wiley.

Taranath, B. 1998. Steel, Concrete, \& Composite Design of Tall Buildings. New York: McGraw-Hill. 